\title{
Contemporary issues relating to transitional care in bladder exstrophy
}

\author{
Fardod O'Kelly, MD'; Daniel Keefe, MD'; Sender Herschorn, MD'; Armando J. Lorenzo, $M D^{4}$
}

'Division of Pediatric Urology, Children's Hospital of Eastern Ontario, Ottawa, ON; 2 Division of Urology, The Ottawa Hospital, Ottawa, ON; ${ }^{3}$ Division of Urology, Sunnybrook Health Sciences Centre, Toronto, ON: " Division of Pediatric Urology, The Hospital for Sick Children, Toronto, ON; Canada

Cite as: Can Urol Assoc J 2018;12(4Supp|1):S15-23. htrp://dx.doi.org/10.5489/cuai.5313

\section{Introduction}

Bladder exstrophy is a rare malformation characterized by an infra-umbilical abdominal wall defect, incomplete closure of the bladder with mucosa continuous with the abdominal wall, epispadias, and alterations in the pelvic bones and muscles. Its incidence is estimated between 1/30 000-1/50 000 live births. ${ }^{1,2}$ From an embryological perspective, mesodermal ingrowth between the ectodermal and endodermal layers of the bilaminar cloacal membrane results in formation of the lower abdominal musculature and pelvic bones. Following mesenchymal ingrowth, downward growth of the rectal septum divides the cloaca into a bladder anteriorly and a rectum posteriorly. The genital tubercles migrate medially and fuse in the midline cephalad to the dorsal membrane before it perforates. The cloacal membrane is subject to premature rupture depending on the extent of the infraumbilical defect. The most recognized theory describes an abnormal lower overdevelopment of the cloacal membrane, which prevents the medial migration of the mesenchymal tissue, leading to disruption of the abdominal wall. The timing of the rupture of this cloacal defect determines the severity of the complex. Central perforations resulting in classic exstrophy have the highest incidence $(60 \%)$, whereas exstrophy variants account for $30 \%$ and cloacal exstrophy for approximately $10 \%$. These conditions are part of a spectrum, the bladder exstrophy-epispadias complex, with cloacal exstrophy on the severe and epispadias on the mild ends of the continuum. Bladder exstrophy remains the most common of these entities and is more common in boys. ${ }^{3-5}$

Prenatal screening studies have demonstrated a sensitivity of $47-71 \%$ to detect bladder exstrophy, with cardinal signs that include: 1) absence of the urinary bladder; 2) lower abdominal bulge; 3 ) small phallus with an anterior scrotum; 4) low set umbilical insertion; and 5) abnormally wide iliac crests. ${ }^{6,7}$ However, a definitive diagnosis is only possible in about a quarter of patients, ${ }^{8}$ and it is arguable (apart from prenatal multidisciplinary awareness and parental counselling) that this has an impact on postnatal outcomes. It may, however, have an impact on the decision to terminate a pregnancy with a potentially affected fetus in jurisdictions where that is allowed. There is an increased risk of approximately $1 / 100$ of developing exstrophy once a sibling has already been affected and, as such, there have been numerous studies attempting to isolate (epi)genetic changes with abnormal imprinting, postulated for abnormal abdominal wall closure, including transcription factors Msx $1 / 2$, IsI $1,{ }^{9} \mathrm{WNT} 3,{ }^{10}$ and p63 isforms; ${ }^{11}$ however, due to the uncommon incidence of these condition, analyses such as these are in their infancy. A large Swedish study across four decades demonstrated that in $92.5 \%$ of the cases, bladder exstrophy was an isolated malformation without associated major abnormalities (in contrast to patients with cloacal exstrophy). A significantly higher proportion of cases had a birth weight $<1500$ g compared with controls, and older maternal age appeared to be the only significant risk factor. ${ }^{12}$

\section{Undescended testes}

Undescended testes (UDT) is a common congenital anomaly seen in pediatric urology. Current American Urological Association and European Association of Urology guidelines recommend referral to a surgical specialist by six months for orchidopexy to be completed by 18 months of age. The reason for delayed referral to six months is because of a mini-hormonal surge of testosterone at approximately three months old. ${ }^{14}$ It may, especially if bilateral, become a potential cause of hypogonadism. It is definitively associated with germ-cell testicular cancer, and evidence from a large Swedish study demonstrated a relative risk of 2.23 for testicular cancer among those who underwent orchiopexy before reaching 13 years, as compared with the Swedish general population; for those treated at 13 years of age or older, the relative risk was $5.40 .{ }^{15}$ There is a significant paucity of data relating to the incidence and prevalence of 


\section{Case}

A 16-year-old male is seen in followup after complete primary repair of exstrophy (CPRE; Mitchell Repair) as a newborn within the first 72 hours of life. The CPRE included bladder plate mobilization and closure without augmentation, as well as bladder neck remodeling, and a disassembly technique for epispadias repair, without pelvic osteotomies. ${ }^{13}$ Dissection included division of the inter-symphyseal ligaments and anatomic placement of the bladder neck and posterior urethra deep into the pelvis, in its expected orthotopic position. He also underwent a left orchidopexy for an undescended testis. He did not undergo ureteric re-implantation. He experienced an uncomplicated recovery during childhood and was kept under close surveillance. He did not have an iatrogenic hypospadias, glans necrosis, or penile skin/tissue loss. He did, however, have a small phallus. He developed bilateral hydronephrosis, however, this was transient, and prophylactic antibiotics were discontinued at toilet training.

It was evident that he had a small functional bladder capacity associated with recurrent lower urinary tract infections (UTIs) likely worsened by incomplete bladder emptying. Urodynamic studies demonstrated a compliant, low-capacity bladder with no evidence of detrusor overactivity, preserved bladder sensation with low-volume urgency, and a voiding efficiency of approximately $30 \%$. It was felt that this was the result of a tight bladder neck and limited bladder volume. At the age of six, following a multidisciplinary review and discussion with his parents, a decision was made to construct an ileal bladder augmentation with an appendicovesicostomy (Mitrofanoff) channel through which his parents - and ultimately the patient — could catheterize in order to keep his bladder empty and provide social continence. Following the advent of puberty, and into adolescence, he became more withdrawn from his adherence to treatment recommendations. As a result, he developed multiple UTIs and bladder stones, which required endoscopic laser lithotripsy and, in one instance, an open cystotomy and bladder stone removal. His upper tracts remained unaffected, with no evidence of dilatation, but at the age of 14, he developed significant, refractory bladder and pelvic pain leading to the concomitant development of depression, body image issues, and school absences lasting 1-2 months at a time. He continued to refuse to correctly catheterize his bladder, despite repeated admission to the hospital, and eventually was referred to the chronic pain service.

This patient illustrates some of the issues associated with transitional care to an adult service and highlights some of the important issues surrounding the care of the adolescent exstrophy patient, such as surveillance for upper tract deterioration, management of the augmented bladder, urinary tract stones, recurrent UTIs, and surveillance for bladder cancer and testicular germ cell tumours (post-orchiopexy). He may also have issues regarding sexual function and, in some cases, fertility. Even though discussion of mental health, body image, social adjustment, and psychosocial issues is critical, these topics fall outside the scope of this paper. Indeed, despite adequate medical and surgical care, patients often experience adverse health outcomes due to unaddressed psychosocial challenges.

UDT in the exstrophy population; however, some reports suggest an incidence as high as $20 \%{ }^{16}$ It is more common in the cloacal exstrophy cohort and may be associated with Spigelian herniae, however, long-term data on fertility and cancer risk in this cohort is unknown. Therefore, the adult urologist needs to be aware of this issue at the time of transition to reinforce these points with their patients. It also critical to consider issues related to "testicular reserve." In exstrophy patients with cryptorchidism, further insults to the gonad may further damage already compromised seminiferous tubules. Thus, patients with recurrent episodes of epididymitis/orchitis related to surgical changes in the posterior urethra and high-pressure voiding could experience further decline in testicular function, placing them at higher risk for infertility and hypogonadism.

\section{Obstetric/gynecological management}

Despite potential issues with fertility in the setting of bladder exstrophy, there are several studies that have demonstrated successful delivery of normal offspring in this cohort. Following a retrospective study of pregnant women with previously repaired exstrophy, Dy et al demonstrated that in the setting of bladder augmentation (75\%) and clean intermittent catheterization (92\%), 78\% women delivered successfully, with a $22 \%$ spontaneous abortion rate. Of note, $100 \%$ deliveries were via caesarian section. The type of incision employed was not associated with an increased risk of complications. ${ }^{17}$ Caesarian sections are preferred in women with functional bladder reconstruction or bladder neck closure in order to decrease the effect of mechanical 
stress on the pelvic floor and to avoid any traumatic injury to the bladder outlet and sphincter mechanism. ${ }^{18}$ There have been reports of vaginal delivery in this patient population, with one recent narrative demonstrating successful delivery with the aid of Duhrssen incisions in the cervix to aid dilatation. ${ }^{19}$ It is advisable, however, to have a urologist present to prevent or adequately address any potential complications to the bladder/ureters.

Pelvic organ prolapse is very common in females with bladder exstrophy, and tends to present at a much younger age, with or without prior sexual activity or pregnancy. The prevalence has been described as high as $50 \%$, with the etiology postulated to be the unique anatomical configuration of pelvic reconstruction: an anterior vaginal introitus, posterior displacement of the dorsorectalis sling, and a weak anterior compartment. The use of slings has had success rates of approximately $70 \%,{ }^{20}$ with the use of bulking agents demonstrating short-term improvements in up to $60 \%$ patients. ${ }^{21}$ The role of pelvic osteotomies at the time of bladder repair on subsequent pelvic organ prolapse has been controversial, but would appear not to eliminate the high rates of prolapse. There is, however, a correlation between the degree of pubic diastasis and future prolapse. ${ }^{22} \mathrm{~A}$ multidisciplinary approach should be employed to counsel females post-exstrophy repair and to plan delivery and childbirth, as well as to ensure that this patient can be referred within a timely fashion to an adult urologist/gynecologist with a subspecialty interest in pelvic medicine and female reconstructive surgery.

\section{Upper tract preservation}

In general, the upper urinary tracts are preserved in newborns with classic bladder exstrophy. The low pressures of an open bladder plate do not predispose to upper tract dilatation; however, upper tract anomalies, such as horseshoe kidney, pelvic kidney, solitary kidney, and renal dysplasia with megaureters, can all be encountered, just as they can in the normal population. In addition, the distal ureteric course is abnormal in the vicinity of the enlarged rectovesical pouch. This leads the ureter to travel laterally across the true pelvis with an inferolateral insertion into the bladder with a J-hook configuration that is associated with a very high incidence of vesicoureteric reflux. Reimplantations can be performed at the time of bladder closure or at the time of bladder neck plasty, and are often performed in a cephalo-trigonal fashion in order to allow better mobilization at the time of bladder neck repair. ${ }^{23}$ Vesicoureteric reflux after exstrophy closure can generally be managed with conservative treatment and interval monitoring of the upper urinary tracts with renal ultrasound. Approximately $11 \%$ of patients undergoing a modern staged exstrophy repair will require reimplantation prior to bladder neck plasty. Exstrophy closure without osteotomy and patients who develop outlet obstruction follow- ing closure appear to be at increased risk for developing high-grade reflux. ${ }^{24}$

The risk of renal calculi in this population is low and arise because of obstruction or biochemical abnormalities associated with urinary diversion, as opposed to intrinsic metabolic abnormalities. Stein et al described an $8.2 \%$ renal calculi prevalence in those with colonic conduits, ${ }^{25}$ but only $1.5 \%$ following a modern staged exstrophy repair. ${ }^{26}$ Importantly, $24 \%$ patients following bladder exstrophy closure can demonstrate renal scarring following dimercaptosuccinic acid scanning regardless of the type of closure or augmentation, with reports of renal transplantation in this population from $1.5-4 \%{ }^{27,28}$ Therefore, it remains important to keep the upper tracts under long-term observation to ensure renal preservation.

\section{Bladder management}

The bladder mucosa may contain hamartomatous polyps, ectopic bowel mucosa, or in the setting of cloacal exstrophy, a segment of bowel. In addition to this, there may be squamous metaplasia with or without the presence of cystitis cystica or cystitis glandularis, the latter of which may increase the future risk of bladder adenocarcinoma. ${ }^{29}$ There is no known association between bladder polyposis and long-term outcomes, however, the presence of polyps may decrease the functional capacity of the bladder and lead to a very challenging closure. Combined cystometrography and electromyography of the external urethral sphincter following complete primary repair of bladder exstrophy has demonstrated normal neurourological findings, including sacral reflex responses, sustained detrusor voiding contraction, and synergic voiding, in all patients postoperatively. ${ }^{30}$ This would suggest a rather normal bladder architecture. However, microarray analysis of bladder exstrophy tissue demonstrates abnormal modelling, with an overexpression of type-3 collage and developmentally immature tissues. This suggests the possibility for maturation and growth following closure; however, there is still a potential risk of reduced compliance with ageing. ${ }^{31}$

Enterocystoplasty is a useful adjunct procedure needed in selected cases with a low capacity and/or poorly compliant bladder to protect the upper urinary tract and attain urinary continence. However, it remains a major surgical undertaking with significant morbidity. Complications may include subsequent malignancy, bowel obstruction, bladder perforation, and bladder stones, as well as medical issues, such as UTIs/pyelonephritis, and gastrointestinal dysfunction. In a large series review of augmentation cystoplasty by Schlomer et al, the 10-year cumulative incidence rates included bladder rupture (2.9-6.4\%), small bowel obstruction $(5.2-10.3 \%)$, bladder stones $(13.3-36.0 \%)$, pyelonephritis $(16.1-37.1 \%)$, cystolithopaxy $(13.3-35.1 \%)$, and 
reaugmentation (5.2-13.4\%). ${ }^{32}$ There have been a number of types of enteral patches used for augmentation, with ileal and colonic being the most common. The use of gastric patches (gastrocystoplasty), while having good continence outcomes, can led to incapacitating hematuria-dysuria syndrome (in up to $64 \%$ of patients) and rare but lethal cases of gastric adenocarcinoma..$^{33}$

Recurrent stone formation is an important consideration in those with an augmented bladder, especially if the bladder neck has previously been closed or reconstructed with the creation of a Mitrofanoff channel. The presence of bladder exstrophy increases the odds ratio (17.4) of developing stones within an augmented bladder and may potentially be as a result of an underlying metabolic anomaly. In one series by Kisku et al, postoperative bladder calculi were noted in $8.8 \%$ of patients following augmentation, with a median time to stone formation of 37.5 months and recurrent febrile UTIs in $10 \%$ patients. ${ }^{34}$ The use of an irrigating protocol into the continent diversion reservoir can reduce the risk of developing calculi by over $80 \%$, however, longterm prospective evidence is scarce. ${ }^{35}$

Bladder rupture is a rare, but dangerous complication of bladder augmentation in the setting of bladder exstrophy. It has often been attributed to poor compliance with clean intermittent catheterization in the adolescent group, when patients are at risk of rebelling to gain some semblance of control over their health and lives. It is potentially lifethreatening and most often requires laparotomy and repair if a patient is systemically compromised. Although it happens in the setting of poor bladder emptying and/or highpressure stressing the weak areas in the augment segment or anastomosis line, the risk of rupture is also present in nonaugmented bladder exstrophy. Data emerging from groups such as Giutronich et al report risk factors that include low capacity $(100 \mathrm{~mL})$, low compliance, and high leak point pressures $\left(>60 \mathrm{cmH}_{2} 0\right) .{ }^{36}$ Clearly the need for continued followup in this cohort in terms of bladder pressures, upper tract deterioration, stones, and the risk of carcinoma, is important and ideally requires a seamless transition from adolescent to adult care.

\section{Bladder neck and continence management}

The primary aim of bladder exstrophy surgery is to tubularize and close the bladder plate with or without ureteric reimplantation, with the associated, but equally important procedures of epispadias repair and bladder neck plasty. Whether this is performed in a complete single-stage, or a modern staged approach, the tenets of renal preservation (i.e., adequate and appropriate bladder emptying) remain valid. In fact, despite a complete primary repair, a significant number of children ( $>35 \%$ ) will still require some kind of formal bladder neck reconstruction, generally employing a modified Young-Dees-Leadbetter approach. ${ }^{37}$ On average, this is performed at around 6-8 years of age. In the early years, it may be advisable to allow the child to void at will into diapers, with clean intermittent catheterization reserved for those cases in which bladder emptying is impaired. Cloacal exstrophy presents a slightly different scenario in that the child may also have neurological deficits and subsequent voiding dysfunction with impaired detrusor activity. Surgery to produce a continent reservoir should be delayed until the child is old enough to participate in self-care. The choice between a catheterizable urethra and an abdominal stoma depends on the urethral and bladder outlet quality, the intellect and dexterity of the child, and the child's orthopedic status with regards to their spine, hips, and ambulation.

Reconstruction of the urethra without adequate circumferential muscular support is a significant problem in bladder neck surgery for urinary incontinence. The definition of incontinence is also controversial, with some groups advocating that it should include any degree of leakage day or night. The Manchester group has reported continence with urethral voiding in $62 \%$ following bladder neck reconstruction, with only $26 \%$ of patients completely dry overnight. ${ }^{38}$ Massanyi et al outlined the importance of bladder capacity at the time of bladder neck reconstruction after failed exstrophy closure and demonstrated that those with a median volume of $100 \mathrm{~mL}$ were more likely to achieve continence than those with a median of $65 \mathrm{~mL}$. Those with the lower capacity were more likely to achieve a favourable result if bladder neck reconstruction was performed concurrently with an enterocystoplasty. ${ }^{39}$ Female classic bladder exstrophy patients, on the other hand, tend to perform a little better than their male counterparts with regards to urinary continence. Purves et al described that $74 \%$ of their female cohort were continent day and night, and were voiding per urethra without augmentation or intermittent catheterization. Social continence, defined as dry for more than three hours during the day but damp at night, was found in a further $10 \% .^{40}$

As an alternative continence strategy, Kavanagh et al reported a 20-year retrospective review of bladder neck closure and formation of an appendicovesicostomy. The success rate of closure was $96 \%$, with a $39 \%$ reintervention rate for secondary complications; however, there was no de novo or worsening hydronephrosis. ${ }^{41}$ The downside of this procedure remains the limited access to the bladder through the Mitrofanoff channel, and followup would be strongly advised into adulthood. There is concern that, as patients with Mitrofanoff channels age, the likelihood of damage to the tract and inability to catheterize will increase.

Irrespective of the preferred initial approach, whether complete primary or modern staged reconstruction, the issue of continued incontinence and complications arising from bladder neck procedures is not insignificant, nor is the need for future intervention. Importantly, little evidence suggests 
that bladder neck dysfunction alone leads to upper tract deterioration; still, followup is crucial following transition from pediatric urological care.

\section{Sexual function}

Patients with bladder exstrophy often have preserved sexual function, libido, and in many cases, are capable of successful fertility. In a recent survey of 113 men with classic bladder exstrophy, Baumgartner et al reported $85 \%$ had been sexually active in their lifetime, $62 \%$ were currently in a relationship, and $41 \%$ were sexually active at least once per week. ${ }^{42}$ As surgical repair techniques have improved, patients with exstrophy have appropriately developed similar goals in their intimate relationships as those unaffected by this condition. ${ }^{43}$ Transitional care of children and adolescents with bladder exstrophy should involve knowledge and patient education regarding the anatomic and sexual functional effects related to bladder exstrophy and its treatment. This should include an informed discussion surrounding fertility.

\section{Penile length}

A primary concern in bladder exstrophy is the smaller phallus compared to controls. Magnetic resonance imaging (MRI) studies have shown that the corporal length is approximately $60 \%$ larger in non-affected patients $(16.1$ vs. $10.1 \mathrm{~cm})$. Much of this deficiency is seen in the anterior portion of the penis. ${ }^{44}$ Penis length appears to be linked to diastasis of the pubic rami. Shorter phalluses are associated with wider diastases and penile length may be improved by osteotomies during initial bladder exstrophy repair. ${ }^{43}$ In addition to the size of the phallus, it is critical to remember the important association with dorsal curvature, which may preclude intercourse if not corrected. Ultimately, penile length is an important functional component for future sexual intercourse. This can be maximized by complete penile degloving, releasing scar tissue from previous surgery, and even releasing the corporal bodies from pubic bone attachments (Kelly procedure). Surgical options have evolved and rely on more aggressive proximal dissection, disassembly, and attempts at a more anatomical reconstruction. For example, Perovic and Djinovic describe opening the penis dorsally for half of its circumference to improve length and reduce curvature. ${ }^{45}$ With variations in surgical approach dictated by surgeon preference and description of new procedures, any further interventions have to take into account the specific steps followed in order to avoid damage to vital penile structures.

\section{Erectile function}

Erectile functional mechanisms should remain intact in bladder exstrophy. Surer et al reported that $87 \%$ of patients experienced erections following epispadias repair. ${ }^{46}$ Unfortunately, there is a high incidence of erectile dysfunction as exstrophy patients progress into adulthood, which is likely multifactorial (surgical injury, specific functional issues with the original congenital defect, concerns with penile appearance, penile curvature). Castagnetti et al compared 19 men with bladder exstrophy with normal controls and identified a significantly higher incidence of erectile dysfunction using the International Index of Erectile Function questionnaire (58 vs. $23 \%$ ). ${ }^{47}$ Woodhouse's data suggested that almost all patients with exstrophy-epispadias complex suffer from erectile deformities, including dorsal curvature and unilateral or bilateral rudimentary corpuses. ${ }^{43}$ It is felt that surgical reconstruction leads to cavernosal injuries and production of iatrogenic chordee. This is supported by cavernosography studies showing that corporal bodies are of equal length at birth and those that underwent multiple reconstructive surgeries exhibited worse erectile dysfunction and curvature than those with a single repair. ${ }^{48,49}$ As surgical technique has improved, we suspect there may be continued improvement in erectile dysfunction rates, although complete long-term objective data are not yet available. It may be, however, that some interventions and complications will have devastating complications affecting penile function, such as loss of tissue due to ischemic injury. There are some reassuring reports. For example, Baumgartner's 2017 survey showed that $70 \%$ of the 113 men had high to very high confidence in achieving and maintaining an erection; $77 \%$ felt the erection would be adequate for penetration. ${ }^{42}$ This is a substantial improvement over prior reported rates of erectile dysfunction. As these patients grow older and transition, focus on erectile function will increase and urologists should be prepared to deal with their particular challenges.

\section{Orgasm, ejaculation, and fertility}

Multiple studies have shown that men with bladder exstrophy can have preserved orgasmic function. Similarly, most men with exstrophy are capable of ejaculation, although the semen parameters and paternity seem to be significantly impacted from exstrophy reconstruction. Ben-Chaim et al studied 16 men and found 10 reported ejaculating a few cubic centimeters of volume, three ejaculated a few drops, and three had no ejaculate. Four of these patients underwent semen analysis revealing azoospermia in three and oligospermia in one. Average ejaculate volume was $0.4 \mathrm{~mL} .{ }^{50}$ Ebert et al studied 21 patients that underwent primary closure and found poor semen parameters in $18 . .^{51}$ This group then identified that men who underwent a single bladder neck procedure were more likely to have higher sperm counts. ${ }^{52}$ Woodhouse reviewed 66 patients with exstrophy who underwent semen analysis and identified $48 \%$ with azoospermia; only $21 \%$ of patients were classi- 
fied as having good sperm quality. ${ }^{43}$ Postulated reasons for the reduced semen parameters include iatrogenic injury to the vas deferens or verumonatum during repair, recurrent epididymorchitis, retrograde ejaculation secondary to an incompetent bladder neck, and underdevelopment of the bulbospongiosus muscle. Irrespective of the etiology, this is an important issue that will gain relevance as the young man matures and becomes interested in fathering children.

Paternity rates in exstrophy are significantly reduced and range from 9-28\%. ${ }^{53-56}$ Bennett reported fertility in only three of 68 men, and Woodhouse showed only four of 72 men had fathered children in his study. ${ }^{57,58}$ In a larger series of 2500 men by Shapiro et al, only 38 men had fathered children. ${ }^{59}$ With this in mind, it is important to counsel men with exstrophy on infertility management. Offering semen analysis to men troubled with infertility can identify the underlying cause. Successful fertility can be accomplished with assistive reproductive therapies, including gamete intrafallopian transfer (GIFT) or intracytoplasmic sperm injection (ICSI). D'Hauwers used GIFT or ICSI in 21 men with exstrophy struggling with infertility and obtained successful pregnancies in all patients. ${ }^{60}$

\section{Transition of the patient to an adult facility}

When the patient is seen in $\mathrm{n}$ adult facility, it is necessary for the receiving urologist to have a summary or complete copy of the medical information from the pediatric facility. In this way, all of his relevant problems can be discussed.

The patient is usually seen with the accompanying parent(s)/guardian(s) in order to establish a new relationship and review the medical history. A copy of the hospital chart may be necessary in order to verify the information. The hospital chart may be large, but it is important for the receiving urologist to know what actual operations have been done. Occasionally, a discharge summary after an admission for a procedure is inaccurate and all subsequent records may contain the same inaccuracy. It is only by plowing through the dictated operating room notes that the one can ascertain what was actually done.

It is important to establish a good relationship not only with the parent(s)/guardian(s), but also with the patient who will assume responsibility for her/his own care and decisions. The history is reviewed along with a general functional enquiry, review of genitourinary symptoms and their management, and targeted physical examination. At the end of the first visit, a decision about further testing and followup is made. If the patient is stable and functioning well, similar long-term management as in the pediatric setting can be arranged. However, if there are unmet needs or ongoing problems, a new plan can be devised.

The case presented earlier in this article describes ongoing difficulty with self-catheterization, bladder pain, recurrent UTI, and bladder stones. There appear to be important psy- chosocial issues that have impacted on his care. The plan for management will probably require the ongoing assistance of other resources that have helped bring the patient to this point. At the outset of the transition, there should be an agreement as to who is going to assume responsibility for complying with specific care recommendations; is it the patient, parents/guardian, or both? Ultimately, as the patient gets older, optimal management would be for him to assume responsibility for decision-making and care.

The patient's depression and body image problems may be difficult to address initially. However, the current functional status of the urinary tract can be evaluated with imaging, cystoscopy, and renal functional testing. Cystoscopy, which may have to be done under general anesthetic, may be helpful to evaluate the patient's pain. The anatomy of the catheterizing channel can be elucidated as to stenosis, tortuosity, and ease of access. Urodynamic studies may be helpful, depending on whether there is incontinence and/or suspicion of a decreased bladder capacity. While the discussion of fertility may be premature in an 18-year-old man, the patient may appreciate a discussion of sexual symptoms and function. Furthermore, various strategies, such as fluids and bladder irrigations to help reduce stones and infections, can be discussed..$^{35}$

A useful guide to management of complications after augmentation cystoplasty can be found in Table $1 .{ }^{61}$

Factors that have been identified to help in transition of patients include an older age of the patients (i.e., when they feel ready for transfer, understanding that the patients have a personal bond with the pediatric urologist and team) and having the transition occur in the same hospital. Patients also want to learn about sexual/fertility aspects. ${ }^{62}$ An article by Stephany et al showed that the most reported fear about transition was that the adult urologist was not informed about the medical history. ${ }^{63}$ Other factors that may aid in the process are adequate planning, education, and preparation of the patients and parents/guardians, and the use of a (nurse) transition coordinator. ${ }^{64}$

The transition of care of the complex pediatric patients, such as those with bladder exstrophy, has been addressed in the recent International Consultation on Incontinence. A number of general and specific recommendations were made, almost entirely on the basis of expert opinion: ${ }^{65}$

- Patients with exstrophy-epispadias complex should be evaluated and managed in specialized centres.

- Persisting incontinence should be evaluated with urodynamics, including measurement of bladder capacity, and its treatment should be individualized based on urodynamic findings.

- Standard techniques for enlargement of a small or high-pressure bladder are appropriate.

- Redo bladder neck reconstruction has a high failure rate and is very unlikely to allow complete, spontaneous voiding. Urethral clean intermittent catheterization may be difficult or impossible. 


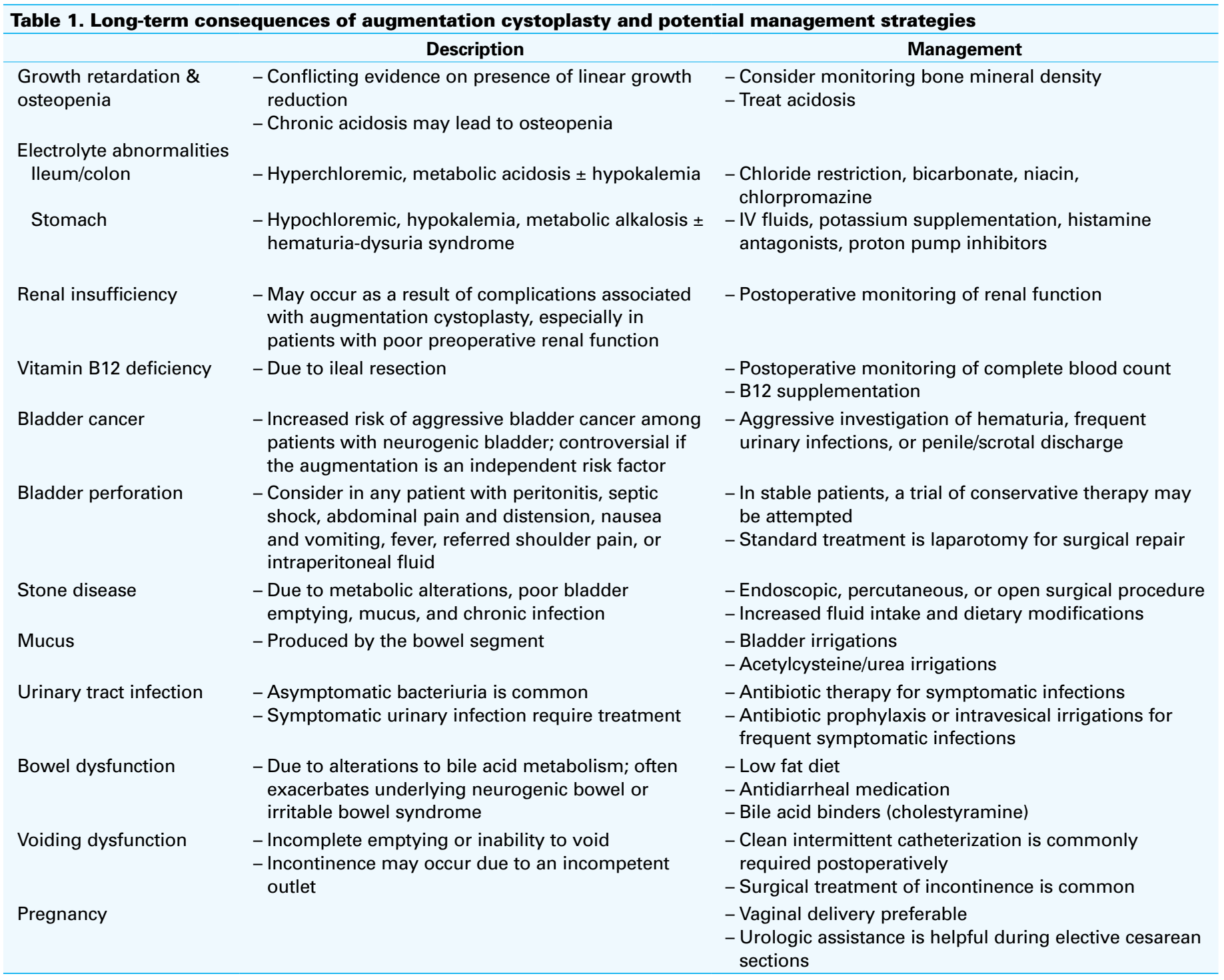

- Suprapubic continent diversion with or without augmentation and with or without bladder neck closure is the best choice for exstrophy patients with urethral failure.

- Lifelong followup is mandatory in terms of continence, voiding efficiency, upper tract status, and other urological complications. Appropriate transitional arrangements must be made to ensure that this is achieved.

\section{Conclusion}

Transition of care is an essential aspect of healthcare delivery. Because of the complexity involved in management of the pediatric exstrophy patient, a similar approach and infrastructure may be needed when the patient transitions to the adult environment. We all aim for a smooth transition; however, we are still learning and evaluating, not only about the long-term outcomes and ramifications of surgical procedures, but also how to set up the infrastructure and obtain resources necessary for transition of these patients into adulthood within our challenging healthcare environment.

Competing interests: The authors report no competing personal or financial conflicts related to this work.

This paper has been peer reviewed.

\section{References}

1. Siffel C, Correa A, Amar E, et al. Bladder exstrophy: An epidemiologic study from the International Clearinghouse for Birth Defects Surveillance and Research, and an overview of the literature. Am J Med Genet C Semin Med Genet 2011;157C:321-32. https://doi.org/10.1002/ajmg.c.30316 
O'Kelly et al

2. Nelson CP, Dunn RL, Wei JT. Contemporary epidemiology of bladder exstrophy in the United States. J Urol 2005;173:1728. https://doi.org/10.1097/01.ju.0000154821.21521.9b

3. Hsieh K, O'Loughlin MT, Ferrer FA. Bladder exstrophy and pheontypic gender determination on fetal magnetic resonance imaging. Urology 2005;65:998-9. https://doi.org/10.1016/j.urology.2004.12.060

4. Sweetser TH, Chisolm TC, Thompson WH. Exstrophy of the urinary bladder: Discussion of anatomic principles applicable to repair with a preliminary report of a case. Minn Med 1952;35:654

5. Mildenberger H, Lkuth D, Dziuba M. Embryology of bladder exstrophy. J Pediatr Surg 1988;23:116. https://doi.org/10.1016/S0022-3468(88)80150-7

6. Ben-Chaim J, Jeffs RD, Sanders RC. Criteria for the prenatal diagnosis of classic bladder exstrophy. Obstet Gynaecol 1995;85:961-4. https://doi.org/10.1016/0029-7844(95)00069-4

7. Fishel-Bartal M, Perlman S, Messing B, et al. Early diagnosis of bladder exstrophy: Quantitative assessment of a low-inserted umbilical cord. J Ultrasound Med 2017;36:1801-5. https://doi.org/10.1002/ jum. 14212

8. Goyal A, Fishwick J, Hurrell R, et al. Antenatal diagnosis of bladder/cloacal exstrophy: Challenges and possible solutions. J Pediatr Urol 2012;8:140-4. https://doi.org/10.1016/i.jpurol.2011.05.003

9. Suzuki K, Matsumaru D, Matsushita S, et al. Epispadias and the associated embryopathies: Genetic and developmental basis. Clin Genet 2017;91:247-53. https://doi.org/10.1111/cge.12871

10. Reutter $\mathrm{H}$, Draaken $M$, Pennimpede $\mathrm{T}$, et al. Genome-wide association study and mouse expression data identify a highly conserved $32 \mathrm{~kb}$ intergenic region between WNT3 and WNT9b as possible susceptibility locus for isolated classic exstrophy of the bladder. Hum Mol Genet 2014 15;23:5536-44.

11. Ching BJ, Wittler L, Proske J, et al. p63 (TP73L) a key player in embryonic urogenital development with significant dysregulation in human bladder exstrophy tissue. Int J Mol Med 2010;26:861-7

12. Reinfeldt Engberg G, Mantel $\ddot{A}$, Fossum M, et al. Maternal and fetal risk factors for bladder exstrophy: A nationwide Swedish case-control study. J Pediatr Urol 2016;12:304.e1-7. https://doi.org/10.1016/i. jpurol.2016.05.035

13. Mitchell ME. Bladder exstrophy repair: Complete primary repair of exstrophy. Urology 2005;65:5-8. https://doi.org/10.1016/i.urology.2004.07.030

14. Guven A, Kogan BA. Undescended testis in older boys: Further evidence that ascending testes are common. J Pediatr Surg 2008;43:1700-4. https://doi.org/10.1016/i.jpedsurg.2008.03.029

15. Pettersson A, Richiardi L, Nordenskiold $A$, et al. Age at surgery for undescended testis and risk of testicular cancer. N Engl J Med 2007;356:1835-41. https://doi.org/10.1056/NEJMoa067588

16. Merksz $M$, Tóth J. The state of the testicle and the epididymis associated with exstrophy of the bladder in undescended testes. Acta Chir Hung 1990;31:297-301.

17. Dy GW, Willihnganz-Lawson KH, Shnorhavorian M, et al. Successful pregnancy in patients with exstrophy-epispadias complex: A University of Washington experience. J Pediatr Urol 2015;11:213.el-6. https://doi.org/10.1016/i.jpurol.2015.04.019

18. Hatch TR, Steinberg RW, Davis LE. Successful term delivery by cesarean section in a patient with a continent ileocecal urinary reservoir. J Urol 1991;146:1111-2. https://doi.org/10.1016/S00225347(17)38016-3

19. Lachica $R$, Chan $Y$, Uquillas KR, et al. Vaginal delivery after Dührssen incisions in a patient with bladder exstrophy and uterine prolapse. Obstet Gynecol 2017;129:689-92. https://doi.org/10.1097/ AOG.0000000000001938

20. Nakhal RS, Deans R, Creighton SM, et al. Genital prolapse in adult women with classical bladder exstrophy. Int Urogynecol J 2012;23:1201-5. https://doi.org/10.1007/s00192-012-1717-z

21. Hosseini $S M$, Zarenezhad $M$, Falahi $S$, et al. Role of bulking agents in bladder exstrophy-epispadias complexes. Afr J Paediatr Surg 2013;10:5-8. https://doi.org/10.4103/0189-6725.109373

22. Anusionwu I, Baradaran N, Trock BJ, et al. Is pelvic osteotomy associated with lower risk of pelvic organ prolapse in postpubertal females with classic bladder exstrophy? J Urol 2012;188:2343-6. https://doi.org/10.1016/i.juro.2012.08.034

23. Braga $L H$, Lorenzo AJ, Jrearz $R$, et al. Bilateral ureteral reimplantation at primary bladder exstrophy closure. J Urol 2010;183:2337-41. https://doi.org/10.1016/i.juro.2010.02.032

24. Tourchi A, Di Carlo HN, Inouye BM, et al. Ureteral reimplantation before bladder neck reconstruction in modern staged repair of exstrophy patients: Indications and outcomes. Urology 2015;85:905-8. https://doi.org/10.1016/i.urology.2014.12.009

25. Stein $R$, Fisch $M$, Stöckle $M$, et al. Colonic conduit in children: protection of the upper urinary tract 16 years later? J Urol 1996;156:1146-50. https://doi.org/10.1016/50022-5347(01)65739-2

26. Baird AD, Nelson CP, Gearhart JP. Modern staged repair of bladder exstrophy: A contemporary series. I Pediatr Urol 2007:3:311e5.

27. Bolduc S, Capolicchio G, Upadhyay J, et al. The fate of the upper urinary tract in exstrophy. J Urol 2002;168:2579-82. htrps://doi.org/10.1016/S0022-5347(05)64220-6

28. Blanco $M$, Medina J, Pamplona $M$, et al. Outcome of renal transplantation in adult patients with augmented bladders. Transplant Proc 2009;41:2382-4. https://doi.org/10.1016/i.transproceed.2009.06.106

29. Novak TE, Lakshmanan Y, Frimberger D, et al. Polyps in the exstrophic bladder. A cause for concern? J Urol 2005;174:1522-6. https://doi.org/10.1097/01.ju.0000179240.25781.1b
30. Borer JG, Strakosha R, Baver SB, et al. Combined cystometrography and electromyography of the external urethral sphincter following complete primary repair of bladder exstrophy. J Urol 2014;191:1547-52. https://doi.org/10.1016/i.juro.2013.10.104

31. Hipp J, Andersson KE, Kwon TG, et al. Microarray analysis of exstrophic human bladder smooth muscle. BJU Int 2008;101:100-5.

32. Schlomer BJ, Copp HL. Cumulative incidence of outcomes and urologic procedures after augmentation cystoplasty. J Pediatr Urol 2014;10:1043-50. https://doi.org/10.1016/i.jpurol.2014.03.007

33. Boissier R, Di Crocco E, Faure $\mathrm{A}$, et al. What is the outcome of pediatric gastrocystoplasty when the patients reach adulthood? BJU Int 2016;118:980-6. https://doi.org/10.1111/bju.13558

34. Kisku S, Sen S, Karl S, et al. Bladder calculi in the augmented bladder: A followup study of 160 children and adolescents. J Pediatr Urol 2015;11:66.el-6. https://doi.org/10.1016/i.jpurol.2014.12.003

35. Hensle TW, Bingham J, Lam J, et al. Preventing reservoir calculi after augmentation cystoplasty and continent urinary diversion: the influence of an irrigation protocol. BJU Int 2004;93:585-7. https://doi.org/10.1111/i.1464-410X.2003.04664.x

36. Giutronich S, Scalabre A, Blanc T, et al. Spontaneous bladder rupture in non-augmented bladder exstrophy. J Pediatr Urol 2016;12:400.el-e5. https://doi.org/10.1016/i.purol.2016.04.054

37. Gargollo $\mathrm{P}$, Hendren WH, Diamond DA, et al. Bladder neck reconstruction is often necessary after complete primary repair of exstrophy. J Urol 2011;185:2563-71. https://doi.org/10.1016/i. juro.2011.01.024

38. Dickson AP. The management of bladder exstrophy: The Manchester experience. J Pediatr Surg 2014;49:244-50. https://doi.org/10.1016/i.jpedsurg.2013.11.031

39. Massanyi EZ, Shah BB, Baradaran N, et al. Bladder capacity as a predictor of voided continence after failed exstrophy closure. J Pediatr Urol 2014;10:171-5. https://doi.org/10.1016/i.jpurol.2013.08.003

40. Purves JT, Baird AD, Gearhart JP. The modern staged repair of bladder exstrophy in the female: A contemporary series. J Pediatr Urol 2008;4:150-3. https://doi.org/10.1016/i.jpurol.2007.08.003

41. Kavanagh A, Afshar $\mathrm{K}$, Scott $\mathrm{H}$, et al. Bladder neck closure in conjunction with enterocystoplasty and Mitrofanoff diversion for complex incontinence: Closing the door for good. J Urol 2012;188:1561-5. https://doi.org/10.1016/i.juro.2012.02.027

42. Baumgartner $T S$, Lue $K M$, Sirisreetreerux $P$, et al. Long-term sexual health outcomes in men with classic bladder exstrophy. BJU Int 2017;120:422-7. https://doi.org/10.1111/bju.13866

43. Woodhouse CR. Sexual function in boys born with exstrophy, myelomeningocele, and micropenis. Urology 1998;52:3-11. https://doi.org/10.1016/S0090-4295(98)00121-6

44. Silver RI, Yang A, Ben-Chaim J, et al. Penile length in adulthood after exstrophy reconstruction. J Uro 1997;157:999-1003. https://doi.org/10.1016/S0022-5347(01)65131-0

45. Perovic SV, Dinovic RP. New insight into surgical anatomy of epispadiac penis and its impact on repair. J Urol 2008;179:689-96. https://doi.org/10.1016/i.juro.2007.09.105

46. Surer I, Baker LA, Jeffs RD, et al. The modified Cantwell-Ransley repair for exstrophy and epispadias: 10-year experience. J Urol 2000;164:1040-3. https://doi.org/10.1016/S0022-5347(05)67245-X

47. Castagnetti M, Tocco A, Capizzi A, et al. Sexual function in men born with classic bladder exstrophy: A norm related study. J Urol 2010;183:1118-22. ht1ps://doi.org/10.1016/i.juro.2009.11.029

48. Woodhouse CR. The management of erectile deformity in adults with exstrophy and epispadias. J Urol 1986;135:932-5. https://doi.org/10.1016/S0022-5347(17)45927-1

49. Brzezinski AE, Homsy YL, Laberge I. Orthoplasty in epispadias. J Urol 1986;136:259-61. https://doi. org/10.1016/S0022-5347(17)44833-6

50. Ben-Chaim J, Docimo SG, Jeffs RD, et al. Bladder exstrophy from childhood into adult life. JR Soc Med 1996;89:39P-46P. https://doi.org/10.1177/014107689608900112

51. Ebert A-K, Reutter H, Ludwig M, et al. The Exstrophy-epispadias complex. Orphanet J Rare Dis 2009;4:23. https://doi.org/10.1186/1750-1172-4-23

52. Ebert AK, Schott $G$, Bals-Pratsch $M$, et al. Long-term followup of male patients after reconstruction of the bladder-exstrophy-epispadias complex: Psychosocial status, continence, renal and genital function. J Pediatr Urol 2010;6:6-10. https://doi.org/10.1016/i.jpurol.2009.06.002

53. Gobet R, Weber D, Horst $M$, et al. Long-term followup (37 to 69 years) in patients with bladder exstrophy treated with ureterosigmoidostomy: Psychosocial and psychosexual outcomes. J Urol 2009;182:1819-23. https://doi.org/10.1016/i.juro.2009.02.064

54. Mesrobian HG, Kelalis PP, Kramer SA. Long-term followup of cosmetic appearance and genital function in boys with exstrophy: Review of 53 patients. J Urol 1986;136:256-8. https://doi.org/10.1016/ S0022-5347(17)44832-4

55. Salem HK, Eisa M. Long-term followup (18-35 years) of male patients with history of bladder exstrophy (BE) repair in childhood: Erectile function and fertility potential outcome. J Sex Med 2012;9:1466-72. https://doi.org/10.1111/i.1743-6109.2011.02536.x

56. Ben-Chaim J, Jeffs RD, Reiner WG, et al. The outcome of patients with classic bladder exstrophy in adult life. J Urol 1996;155:1251-2. https://doi.org/10.1016/S0022-5347(01)66233-5

57. Bennett AH. Exstrophy of bladder treated by ureterosigmoidostomies. Long-term evaluation. Urology 1973;2:165-8. https://doi.org/10.1016/0090-4295(73)90252-5 
58. Woodhouse CRJ. The gynecology of exstrophy. BJU Int 1999;83:34-8. https://doi.org/10.1046/i.1464410x.1999.0830s3034.x

59. Shapiro E, Jeffs RD, Gearhart JP, et al. Muscarinic cholinergic receptors in bladder exstrophy: Insights into surgical management. J Urol 1985;134:308-10. https://doi.org/10.1016/S0022$5347(17) 47139-4$

60. D'Hauwers KWM, Feitz WFJ, Kremer JAM. Bladder exstrophy and male fertility: Pregnancies after ICSI with ejaculated or epididymal sperm. Fertil Steril 2008;89:387-9. https://doi.org/10.1016/i.fertnstert.2007.03.005

61. Herschorn S, Welk BK. Augmentation cystoplasty. In Complications of Female Incontinence and Pelvic Reconstructive Surgery, 2nd edition (Goldman, HB, ed.) Humana Press, New York, NY, 2017, pp. 245264. https://doi.org/10.1007/978-3-319-49855-3_23

62. Harhuis $A$, Cobussen-Boekhorst $H$, Feitz $W$, et al. Five years after introduction of a transition protocol: An evaluation of transition care for patients with chronic bladder conditions. J Pediatr Urol 2017. Epub ahead of print. https://doi.org/10.1016/i.jpurol.2017.09.023
63. Stephany $H A$, Ching $C B$, Kaufman MR, et al. Transition of urologic patients from pediatric to adult care: A preliminary assessment of readiness in spina bifida patients. Urology 2015;85:959-63. https://doi.org/10.1016/j.urology.2014.12.019

64. Dunn K, Rogers J. Discharge facilitation: An innovative PNP role. J Pediatr Health Care 2016;30:499-505. https://doi.org/10.1016/i.pedhc.2015.10.004

65. Goldman HB, Averbeck MA, Bruschini $H$, et al. Surgical Treatment of Urinary Incontinence in men. In: Abrams MT, Cardozo L, Wein A, Wagg A, eds. 6 th International Consultation on Urinary Incontinence. Tokyo, Japan 2016.

Correspondence: Dr. Armando J. Lorenzo, Division of Pediatric Urology, The Hospital for Sick Children, Toronto, ON, Canada; armando.lorenzo@sickkids.ca 